\section{Omalizumab mitigates anaphylaxis during ultrarush honey bee venom immunotherapy in monoclonal mast cell activation syndrome}

Elizabeth Nicole da Silva, MBBS, BA, FRACP, FRCPA ${ }^{a, b}$, and Katrina Louise Randall, MBBS, PhD, FRACP, FRCPA ${ }^{a, b}$

\section{Clinical Implication}

- Elevated baseline serum tryptase confers an increased risk of anaphylaxis during venom immunotherapy. We describe the first case of the successful use of omalizumab during an ultrarush protocol for venom immunotherapy in a patient with monoclonal mast cell activation syndrome.

\section{TO THE EDITOR:}

Venom immunotherapy (VIT) is indicated for all individuals with sting-induced anaphylaxis and evidence of venom-specific IgE. ${ }^{1}$ For patients with a concurrent proliferative mast cell disorder, such as monoclonal mast cell activation syndrome (MMAS) or mastocytosis, which confer increased risk of venom allergy, ${ }^{2}$ life-long VIT has been recommended on the basis of case reports that describe fatal anaphylaxis due to field stings after discontinuation of VIT. ${ }^{3}$ Elevated baseline serum tryptase in the setting of sting-induced anaphylaxis, including but not exclusively in mastocytosis, confers an increased risk of anaphylaxis during VIT. ${ }^{4}$

Several case reports have indicated the efficacy of omalizumab, a humanized monoclonal IgG1 anti-IgE Fct antibody in mitigating the risk of anaphylaxis in high-risk settings during VIT. This has been demonstrated by using both pretreatment and maintenance omalizumab dosing to treat patients at high risk without mastocytosis who were receiving modified rush $^{5}$ or ultrarush ${ }^{6}$ VIT, and both during initiation of modified rush $^{7}$ and as high-dose monthly therapy during maintenance ${ }^{8}$ VIT in individuals with mastocytosis. However, not all case reports support the efficacy of omalizumab during immunotherapy, ${ }^{9}$ and it remains unclear as to what other factors, apart from the kind of protocol used and the presence or absence of monoclonal mast cell disorders contribute to clinical success. An accepted mechanism of action is via downregulation of $F_{c} \in R I$ in response to depletion of circulating $\operatorname{IgE},{ }^{10}$ thereby reducing mast cell responsiveness. However, a clinical report that described the efficacy of omalizumab in sting-induced anaphylaxis in a patient with mastocytosis but without demonstrable venom-specific $\mathrm{IgE}$ suggests that, despite the lack of cellular evidence, ${ }^{10}$ an additional mechanism of action, such as mast cell apoptosis via reduced $\mathrm{IgE}$ binding with subsequent reduction in mast cell burden, cannot be discounted. ${ }^{11}$

We describe a case of omalizumab used to mitigate anaphylaxis during ultrarush honey bee VIT in a patient with MMAS. This case is unique in that the target dose of $100 \mu \mathrm{g}$ was safely attained within 3 days, with maintenance doses continued safely thereafter for more than 12 months to date, even after omalizumab therapy had been stopped.

\section{CASE REPORT}

A 52-year-old man presented to the outpatient department at our institution with a history of a single episode of anaphylaxis that occurred after a sting from a honey bee sustained while he was driving. Within seconds, he became short of breath, flushed, and experienced an acute deterioration of his vision, which necessitated him to pull over to the side of the road, whereupon he vomited and became unconscious. He was taken to the emergency department by ambulance and found to be profoundly hypotensive. All symptoms responded rapidly to intramuscular adrenalin. He had had previous bee stings with no adverse effect. His other medical history included hypertension, well-controlled asthma, and hyperlipidemia, and he was an ex-smoker. Investigations revealed an elevated total $\operatorname{IgE}$ level $(211 \mathrm{kU} / \mathrm{L}$; reference range, $<100 \mathrm{kU} / \mathrm{L})$ and a positive honey bee venom-specific IgE level (41.9 kU/L). He commenced honey bee VIT by our standard protocol but he experienced anaphylaxis within minutes after the first dose $(0.01 \mu \mathrm{g})$, characterized by generalized flushing and by a sudden and otherwise unprovoked change in affect and behavior, with the patient appearing agitated, shouting verbally abusive remarks at staff, and attempting to get out of the bed, all of which resolved abruptly with the administration of intramuscular adrenalin.

The patient was investigated further, and an elevated baseline tryptase level $(22 \mu \mathrm{g} / \mathrm{L}$; reference range, $<15 \mu \mathrm{g} / \mathrm{L})$ was detected on 2 occasions. Analysis of bone marrow aspirate and trephine did not identify abnormal or increased mast cells but did confirm the presence of the KIT D $816 \mathrm{~V}$ mutation. A diagnosis of MMAS with honey bee venom allergy was made, and he was commenced on combination $\mathrm{H} 1$ and $\mathrm{H} 2$ oral antihistamines. In preparation for another trial of VIT, he subsequently received 3 doses of omalizumab (300 mg, subcutaneously) 10 weeks, 6 weeks, and then 2 weeks before recommencing VIT. Due to the patient living in a rural location, approximately $250 \mathrm{~km}$ from our tertiary institution, and with road travel the only practical option for the patient, we elected to administer VIT by using an ultrarush protocol (Table I) in a high-dependency unit, whereas the preliminary doses of omalizumab were given in the treatment area of our unit. Resumption of VIT was complicated on day 1 by mild agitation, characterized by increased motor activity, louder and more-rapid speech, and irritability, at a cumulative dose of $21.01 \mu \mathrm{g}$ (Table I). He was not flushed, there was no evidence of breathing difficulty, and his blood pressure and peak expiratory flow were consistent with baseline. He was treated with further oral antihistamine, and the agitation resolved quickly. Resumption of VIT the following day, with only minor modifications to the schedule, was uncomplicated apart from large local reactions at injection sites that settled with oral antihistamine and the application of ice packs. Day 3, again with minor schedule modifications and large local reactions, otherwise proceeded uneventfully. He tolerated subsequent maintenance VIT at a dose of $100 \mu \mathrm{g}$ at 1 week, 3 weeks, and monthly 
TABLE I. Ultrarush VIT protocol; the 2 right-hand columns list amendments to the protocol made due to mild agitation on day 1

\begin{tabular}{|c|c|c|c|c|c|}
\hline \multicolumn{4}{|c|}{ Protocol } & \multirow[b]{2}{*}{$\begin{array}{c}\text { Actual dose } \\
\text { received }(\mu \mathrm{g})\end{array}$} & \multirow{2}{*}{$\begin{array}{c}\text { Actual } \\
\text { cumulative } \\
\text { dose } / \mathrm{d}(\mu \mathrm{g})\end{array}$} \\
\hline Day & $\begin{array}{c}\text { Dose } \\
\text { no. }\end{array}$ & $\begin{array}{l}\text { Dose } \\
(\mu \mathrm{g}) \\
\end{array}$ & $\begin{array}{l}\text { Cumulative } \\
\text { dose } / \mathrm{d}(\mu \mathrm{g})\end{array}$ & & \\
\hline \multirow[t]{10}{*}{1} & 1 & 0.01 & 41.01 & 0.01 & 21.01 \\
\hline & 2 & 0.1 & & 0.1 & \\
\hline & 3 & 0.3 & & 0.25 & \\
\hline & 4 & 0.6 & & 0.5 & \\
\hline & 5 & 1 & & 0.75 & \\
\hline & 6 & 1 & & 1 & \\
\hline & 7 & 3 & & 2 & \\
\hline & 8 & 5 & & 5 & \\
\hline & 9 & 10 & & $\begin{array}{l}10 \text { (mild } \\
\text { agitation) }\end{array}$ & \\
\hline & 10 & 20 & & - & \\
\hline \multirow[t]{5}{*}{2} & - & - & 160 & 10 & 115 \\
\hline & - & - & & 20 & \\
\hline & 11 & 35 & & 35 & \\
\hline & 12 & 50 & & 50 & \\
\hline & 13 & 75 & & - & \\
\hline \multirow[t]{2}{*}{3} & - & - & 100 & 75 & 175 \\
\hline & 14 & 100 & & 100 & \\
\hline
\end{tabular}

thereafter. Monthly doses of omalizumab were continued during the early maintenance period, given half an hour before VIT, for a further 6 months, which totalled 9 doses of omalizumab. Since then, he has tolerated a further 13 months of monthly maintenance VIT without omalizumab and has been discharged to his general practitioner with a recommendation that he receive lifelong maintenance honey bee VIT in his home town.

As far as we are aware, this is the first case report of omalizumab used during the administration of a specifically ultrarush protocol for honey bee VIT in a patient with MMAS or mastocytosis. An ultrarush immunotherapy protocol may be especially relevant in patients with proliferative mast cell disorders. Apart from any geographic considerations, the expense and limited availability of both off-label omalizumab, high-dependency-unit day-bed stay, and specialized nursing staff make an ultrarush protocol a more viable option, but only if patient safety is not compromised. Although the conclusions that can be drawn from a single case, by necessity, are limited, this report illustrates the potential safety and efficacy of an ultrarush VIT protocol in patients with proliferative mast cell disorders when administered in conjunction with omalizumab. a Department of Immunology, The Canberra Hospital, Canberra, Australia

${ }^{\mathrm{b}}$ The Australian National University Medical School, Australian National University, Canberra, Australia

Novartis kindly donated 3 doses of omalizumab for use with this patient.

Conflicts of interest: K. L. Randall received 3 doses of the drug used in the study on compassionate grounds from Novartis. E. N. da Silva declares no relevant conflicts of interest.

Received for publication May 16, 2013; revised June 27, 2013; accepted for publication July 10, 2013.

Available online September 9, 2013

Cite this article as: da Silva EN, Randall KL. Omalizumab mitigates anaphylaxis during ultrarush honey bee venom immunotherapy in monoclonal mast cell activation syndrome. J Allergy Clin Immunol Pract 2013;1:687-8. http://dx.doi .org/10.1016/j.jaip.2013.07.004.

Corresponding author: Elizabeth N. da Silva, MBBS, BA, FRACP, FRCPA, Department of Immunology, The Canberra Hospital, Yamba Dr, Garran 2605, Australian Capital Territory, Australia. E-mail: Elizabeth.daSilva@act.gov.au.

2213-2198/\$36.00

(C) 2013 American Academy of Allergy, Asthma \& Immunology

http://dx.doi.org/10.1016/j.jaip.2013.07.004

\section{REFERENCES}

1. Krishna MT, Ewan PW, Diwakar L, Durham SR, Frew AJ, Leech SC, et al. Diagnosis and management of hymenoptera venom allergy: British Society for Allergy and Clinical Immunology (BSACI) guidelines. Clin Exp Allergy 2011; 41:1201-20.

2. Bonadonna P, Perbellini O, Passalacqua G, Caruso B, Colarossi S, Dal Fior D, et al. Clonal mast cell disorders in patients with systemic reactions to Hymenoptera stings and increased serum tryptase levels. J Allergy Clin Immunol 2009;123:680-6.

3. Oude Elberink JNG, de Monchy JGR, Kors JW, van Doormaal JJ, Dubois AEJ. Fatal anaphylaxis after a yellow jacket sting, despite venom immunotherapy, in two patients with mastocytosis. J Allergy Clin Immunol 1997;99:153-4.

4. Rueff F, Przybilla B, Biló MB, Müller U, Scheipl F, Aberer W, et al. Predictors of side effects during the buildup phase of venom immunotherapy for Hymenoptera venom allergy: The importance of baseline serum tryptase. J Allergy Clin Immunol 2010;126:105-11.

5. Galera C, Soohun N, Zankar N, Caimmi S, Gallen C, Demoly P. Severe anaphylaxis to bee venom immunotherapy: efficacy of pretreatment and concurrent treatment with omalizumab. J Investig Allergol Clin Immunol 2009; 19:225-9.

6. Schulze J, Rose M, Zielen S. Beekeepers anaphylaxis: successful immunotherapy covered by omalizumab. Allergy 2007;62:963-4.

7. Kontou-Fili K. High omalizumab dose controls recurrent reactions to venom immunotherapy in indolent systemic mastocytosis. Allergy 2008;63:376-8.

8. Kontou-Fili K, Filis CI. Prolonged high-dose omalizumab is required to control reactions to venom immunotherapy in mastocytosis. Allergy 2009;64:1384-92.

9. Soriano Gomis V, Gonzalez Delgado P, Niveiro Hernandez E. Failure of omalizumab treatment after recurrent systemic reactions to bee-venom immunotherapy. J Investig Allergol Clin Immunol 2008;18:225-6.

10. Beck LA, Marcotte GV, MacGlashan D, Togias A, Saini S. Omalizumabinduced reductions in mast cell Fc $\epsilon$ RI expression and function. J Allergy Clin Immunol 2004;114:527-30.

11. Kontou-Fili K, Filis CI, Voulgari C, Panayiotidis PG. Omalizumab monotherapy for bee sting and unprovoked "anaphylaxis" in a patient with systemic mastocytosis and undetectable specific IgE. Ann Allergy Asthma Immunol 2010;104:537-9. 
Reproduced with permission of the copyright owner. Further reproduction prohibited without permission. 